\title{
XXV. On the conducting power of iodine, bromine, and chlorine for electricity
}

\section{Edward Solly Jun. Esq.}

To cite this article: Edward Solly Jun. Esq. (1836) XXV. On the conducting power of iodine, bromine, and chlorine for electricity , Philosophical Magazine Series 3, 8:45, 130-134, DOI: $10.1080 / 14786443608648821$

To link to this article: http://dx.doi.org/10.1080/14786443608648821

册 Published online: 01 Jun 2009.

Submit your article to this journal $₫$

Q View related articles $\asymp$ 


\section{[ 130$]$}

XXV. On the Conducting Power of Iodine, Bromine, and Chlorine for Electricity. By Edward Soluy, Jun., Esq. *

IN the Philosophical Magazine and Journal of Science, No. 42, p. 441, Dr. Inglis; in his prize essay on iodine, states that he has found solid iodine to be a conductor of electricity. In my own observations I had always found it a nonconductor; I was therefore led to repeat my experiments with greater care, and the following are the results.

1. I first sought for conducting power by the beautiful method proposed by Dr.Wollaston, namely, the effect produced upon the tongue when two metals of different degrees of oxidibility, placed on either side of it, are made to communicate with each other, through any portion of conducting matter. Iodine was melted in a thin glass tube, which, when cold, was broken, and the iodine obtained in a solid state; a portion was then placed between the extremities of the two metals; but on no occasion was the least taste produced; though if the metals were connected together only by being immersed in spring water, a taste was immediately perceived. When the two terminations of the metal plates are made to dip into a solution of iodine in water, a strong taste is perceived.

2. In order to examine the conducting power with the voltaic battery, and where the application of the tongue would have been uncertain and inconvenient, the following apparatus was used. B D J K is a slip of glass, on which two pieces of bibulous paper, $\mathbf{E}$ and $F$, soaked in a solution of iodide of potassium, are placed. The wire $A$, resting upon $\mathrm{E}$, was always made the anode $\mathrm{C}$; or that resting on $\mathrm{F}$, the cathode: thus arranged, of course no action took place. But if a wire was made to touch with one end the paper $F$, and with the other end the paper $\mathrm{E}$, the usual series of phænomena took place; iodine was evolved at $A$, and also at that end of the temporary wire which rested upon $\mathbf{F}$. The fluid to be examined was placed in a glass tube, $G$, having two platinum wires, $H$ and I, fused into it; they were separated from each other by an interval of about the $\frac{1}{20}$ th of an inch; thus, when the two wires were made to rest upon the two pieces of paper $F$ and

* Communicated by the Author.-It appears that we were correct in thinking that Dr. Inglis's experiments on this subject would attract attention. He has favoured us with the following reply to our note respecting it apperided to the first part of his paper, as referred to above. "In answer to the note regarding the conducting power of iodine, I may just quote a sentence from my original Essay: 'The preparation sent in, shows the state in which iodine requires to be, for the transmission of Electricity. It has merely been fused in a glass tube, and the tube afterwards broken from around it. But although it still continues to conduct, it did so with far more energy when in the fluid state.' Dec. 18, 1835."-EDit. 
On the Conducting Porver of Iodine, \&c. for Electricity. 131

E, any current that passed would be rendered evident by the decomposition of the iodide of potassium.

3. Iodine was fused in the tube $G$, and the end of its two wires, $I$ and $H$, were placed on the papers $E$ and $F$, as soon as the iodine was solid; not the least spot of iodine was perceived at $\mathbf{E}$ or $\mathbf{H}$, though the battery employed consisted of sixty pairs of plates, four inches square, in very strong action: a small piece of wire was then made to connect $I$ and $H$, just where they are fused into the glass tube; and though they were but momentarily connected, yet a dark spot of iodine was produced; thus proving that the only interruption to the current was that in the tube $G$, between the wires $H$ and $I$.

Fig. 1.

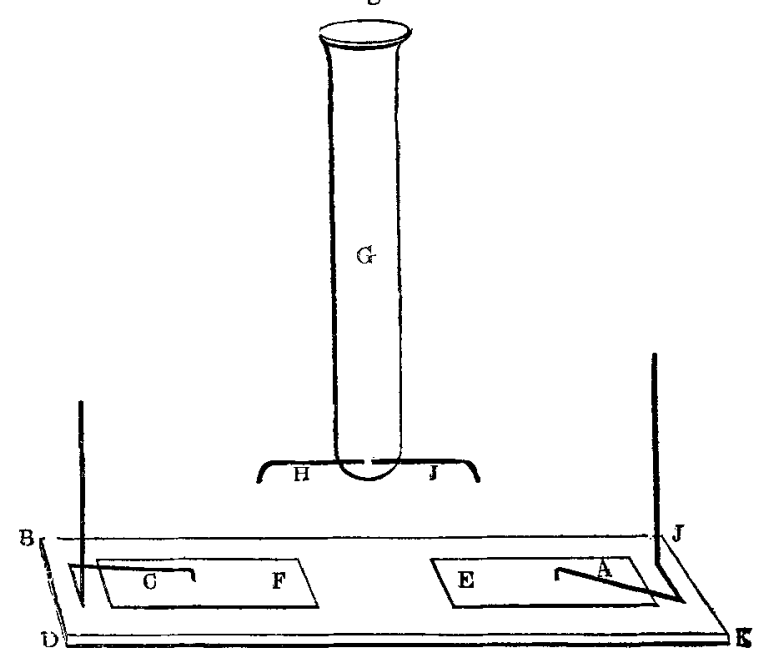

4. The iodine was then replaced by a solution of iodine in water; the current passed immediately, and produced its full effect at $\mathrm{A}$ and $\mathrm{H}$ : the water only, however, was decomposed, and no peculiar action was occasioned. But this is certainly no proof that iodine is at all a conductor; we very well know that sulphuric acid added to water improves its conducting power, and so do phosphoric and sulphurous* acids, and many other acknowledged nonconductors; indeed, were it not for the addition of certain nonconducting substances, such as sulphuric acid, the decomposition of water would hardly be effected by the voltaic battery. Again, M. De la Rive $\dagger$ has remarked that bromine and chlorine are nonconductors, and

* See Phil. Trans. 1834 ; Faraday's Seventh Series, No. 755. [or Lond. and Edinb. Phil. Mag., vol.v. p. 257.-EnIT.]

$\dagger$ Annales de Chimie et de Physique, 1827, vol. xxxv. 
that pure water is also one; but that a solution of bromine or chlorine in water is a good conductor. A solution of iodine in æther also allowed the transmission of electricity, but in a less degree.

5. Iodine is soluble in carburet of sulphur, forming a fine pinkish red solution; when boiled in it, a considerable quantity is dissolved, which, upon cooling, is again deposited in crystals : neither the hot nor the cold solution conducted the electricity.

6 . Iodine is also soluble in chloride of sulphur, forming a deep red liquid; much more is taken up by boiling, and upon cooling, crystals, probably of unaltered iodine, are precipitated. Dr. Inglis says that "iodine and chloride of sulphur form a compound, having many of the properties of bromine; but that it is decomposed by galvanism, which the real bromine is not." The result of my experiments was different, for I found that when the red liquid was submitted to the electric current in $\mathrm{G}$, it formed a perfect barrier to the passage of the electricity, and it is very certain that decomposition cannot be effected without conduction. Perhaps Dr. Inglis will state how the experiment was performed, and at which electrode the iodine was evolved, or what were the substances evolved.

7. Bromine I found to be a nonconductor when placed in the tube $\mathrm{G}$; a solution of bromine in water was a much better conductor than pure water, as M. De la Rive has mentioned (see the above-quoted memoir). In these and all the following experiments here described, the test of the wire (3.) was applied.

8. A solution of bromine in æther conducts. Æther seems to have a remarkable action on the colours of solutions containing bromine, for whenever it is added to any of the deep red solutions containing bromine, or the iodide of bromine, the colour is rendered considerably lighter, so that an almost opake solution becomes pale yellow, and quite transparent.

9. Bromine is soluble in chloride of sulphur, in the same way as iodine, forming a beautiful red solution: this proved a nonconductor; but upon adding a few drops of æther it became a conductor. Bromine is also soluble in carburet of sulphur, forming a splendid red solution, similar to the forementioned one: this was likewise a nonconductor; but a few drops of æther rendered it a conductor.

10. Periodide of bromine was a conductor; the current transmitted by it was fully able to decompose the iodide of potassium at $\mathrm{E}$ and $\mathrm{F}$; but thedecomposition of water, also placed in the circuit, was effected with some difficulty. A little water was now added to the periodide of bromine; the water floated at the top, and dissolved a small portion of it: the water and the 
iodide of potassium indicated that the current was passing; but the liquids in the tube $G$ were not visibly affected.

11. An aqueous solution of the periodide of bromine being put into the tube G, conducted, and was briskly decomposed; but both the platinum wires remained bright and clean, and neither iodine, bromine, nor any compound of them, was evolved or deposited on either electrode, though the action was continued for some time.

12. A solution of the periodide of bromine was a good conductor, and the current transmitted had sufficient intensity for the electrolyzation of water. Solutions of the periodide, in chloride of sulphur and carburet of sulphur, were nonconductors; upon the addition, however, of a few.drops of æther, they became good conductors.

13. The conducting power of chlorine was next tried, and for this purpose the following apparatus was employed: $\mathrm{A} \mathrm{B} \mathrm{C}$,

Fig. 2.

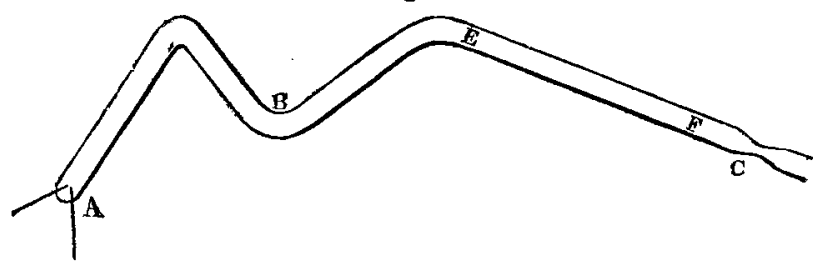

fig. 2, is a glass tube $\frac{4}{10}$ ths of an inch in diameter, having two platinum wires fused into it at $A$, so as to be separated the $\frac{1}{10}$ th of an inch from each other; the tube being then inverted, the space from $\mathrm{E}$ to $\mathrm{F}$ was filled with peroxide of manganese and muriatic acid; the end $\mathbf{C}$ was then carefully closed by a spirit lamp, and the whole being cooled, it was placed in the position represented in the figure, the space from $\mathbf{E}$ to $\mathbf{C}$ being filled with a mixture for generating the chlorine, the other parts of the tube having been carefully kept dry. Heat was then applied to $C$, and $B$ was immersed in ice-cold water; as soon as a sufficient quantity of liquid had collected in B, A was immersed in a mixture of ice and salt, and $B$ was gently warmed; by this means the liquid chlorine was rectified, and obtained quite free from water or other extraneous fluids at $\mathbf{A}$. Matters being thus arranged, and sufficient chlorine having been condensed, the tube was placed in the same position as the tube $\mathbf{G}$ in the former figure, one of the two platinum wires resting on the moistened paper $F$, the other upon $E$, fig. 1 . I was at first surprised by finding it a conductor; but when the tube was carefully wiped, so as to be quite free from all adhering salt from the freezing mixture, it proved a perfect nonconductor. 
14. The crystallized hydrate of chlorine was then put in the tube G, fig. 1: it proved a nonconductor. A strong solution of chlorine, placed in the same situation, was a good conductor.

From these experiments the following conclusions may be drawn: 1st, that iodine, bromine, and chlorine are nonconductors; 2ndly, that they improve the conducting power of badly-conducting eiectrolytes; and $3 \mathrm{rdly}$, that two nonconductors combining can form a body which can conduct electricity, and which resists the decomposing power of the voltaic battery.

7, Curzon Street, 15th January, 1836.

XXVI. Description of the Aurora Borealis of November 16, 1835. By W. Sturgeon, Lecturer on Experimental Philosophy at the Honourable East India Company's Military Academy, \&c. \&c. **

A $\mathrm{N}$ aurora borealis of a very unusual character was seen in A this neighbourhood, and I imagine over a large tract of country, on Wednesday evening the 16th instant. I was walking from Greenwich to Woolwich between nine and ten o'clock; and when I had arrived at the top of Maize Hill, by the side of Greenwich Park, then about ten minutes past nine, my attention was first attracted by the fine light of the aurora in the north. I walked on a little further till a good opening to the northern horizon presented itself from the road leading from Maize Hill to Mr. Angerstein's estate. At this opening I made a determined stand, for the purpose of observing any novel phænomenon which the aurora might happen to present.

At this time it consisted principally of a very extensive lateral range, on both sides of the pole star, of vertical streamers, which were pencilling the northern heavens from about $15^{\circ}$ above the horizon to Cassiopeia's Chair, then about the meridian; and so uniform was their arrangement and splendour that they presented one sheet of yellowish white light, the most intense at the base, and becoming more and more faint as they proceeded upwards, until quite lost at their terminal altitudes.

This appearance of the aurora had but just stamped its impression on my mind, when in one moment the whole of the northern heavens appeared in one complete state of undulating commotion, heaving upwards in rapid succession immense waves of light $\dagger$, which, like the streamers which preceded

* Communicated by the Author.

f These waves were seen at Milton next Gravesend by my scientific friend Mr. Swinny; and I beg to acknowledge the obligation I am placed 